\title{
Editorial \\ Identification of women with an increased risk of developing radiation-induced breast cancer
}

\author{
Elisabeth Cardis ${ }^{1}$, Janet Hall ${ }^{2}$ and Sean V Tavtigian ${ }^{1}$
}

\author{
${ }^{1}$ International Agency for Research on Cancer, cours Albert Thomas, 69372 Lyon Cedex 08, France \\ 2Institut Curie-Recherche: INSERM U612, Bâtiments 110-112 Centre Universitaire, 91405 Orsay, France
}

Corresponding author: Elisabeth Cardis, cardis@iarc.fr

Published: 29 June 2007

Breast Cancer Research 2007, 9:106 (doi:10.1186/bcr1733)

This article is online at http://breast-cancer-research.com/content/9/3/106

(c) 2007 BioMed Central Ltd

See related research article by Broeks et al., http://breast-cancer-research.com/content/9/2/R26

\begin{abstract}
In the previous issue of Breast Cancer Research, Broeks and collaborators present the results of a study suggesting that germline mutations in BRCA1, BRCA2, ATM or CHEK2 may double the risk of radiation-induced contralateral breast cancer following radiotherapy for a first breast cancer. The assocation appeared to be strongest among women who were below the age of 40 at the time of their first breast cancer and among women who developed their second cancer 5 years or more after the first. While there were a number of methodological issues that might limit the conclusions drawn from this paper, this is one of several recent studies suggesting that carriers of pathogenic alleles in DNA repair and damage recognition genes may have an increased risk of breast cancer following exposure to ionising radiation, even at low doses. This finding has important implications for the protection of breast cancer patients and their close relatives. If confirmed, mutation carriers may wish to consider alternatives to Xray for diagnostic purposes. The need for tailored cancer treatment strategies in carriers should also be evaluated carefully.
\end{abstract}

Breast cancer $(\mathrm{BC})$ is the most common cancer and one of the leading causes of death among women worldwide, with nearly 1,000,000 new cases per year [1]. Known risk factors include genetic susceptibility and exposure to ionising radiation [2]. The risks are highest among women exposed in childhood and adolescence and are among the highest known radiation-related risks for any cancer type [3].

Associations have been reported between inherited $B C$ and pathogenic alleles in ten different genes involved in pathways critical for genomic integrity [4]. BRCA1 and BRCA2 mutations confer very high risks of breast and ovarian cancer. p53 and PTEN mutations lead to very high $\mathrm{BC}$ risks associated with rare cancer syndromes. Mutations in CHEK2, ATM, NBS1, RAD50, BRIP1, and PALB2 are associated with at least a doubling of $B C$ risk. Because many of these genes are specifically implicated in the response to ionising radiation, women who carry pathogenic alleles in these genes might be more sensitive to radiation-induced $\mathrm{BC}$ than non-carriers, as suggested by recent studies $[5,6]$

In the previous issue of Breast Cancer Research, Broeks and collaborators [7] present results suggesting that pathogenic alleles in four specific DNA repair and damage recognition genes increase the risk of radiation-induced contralateral $\mathrm{BC}$ following radiotherapy for a first BC.

The study used a case-only design and included 247 cases of contralateral BC diagnosed at two of the main cancer treatment institutions in the Netherlands among women who had a first BC before age 50 in the period 1966 to 2000. Overall, $21 \%$ of cases carried a pathogenic allele in BRCA1, BRCA2, CHEK2 or ATM. The percentages were $24.3 \%$ among women who received radiation therapy for their first cancer (169) and 12.8\% among those who did not (78). The odds ratio (OR) of developing contralateral $\mathrm{BC}$ following radiation therapy was 2.18 (95\% confidence interval (Cl) 1.03-4.62) in women carrying a pathogenic allele compared to women without. The assocation appeared to be strongest among women aged less than 40 at the time of their first BC (OR 2.77, 95\% Cl 0.74-10.39) and among women who developed their second cancer 5 years or more after the first (OR 2.51, 95\% Cl 1.03-6.10). The OR appeared to be lowest for mutations in BRCA1 and highest for mutations in CHEK2, although these results were based on small numbers of cases and are not statistically significantly different.

In interpreting the results of this study, a number of methodological issues must be kept in mind. Firstly, because of the techniques used for the screening of BRCA1 and BRCA2, a number of sequence variants will have been missed, disproportionately missense substitutions and particularly in

$\mathrm{BC}=$ breast cancer $; \mathrm{Cl}=$ confidence interval $; \mathrm{OR}=$ odds ratio. 
BRCA2. Secondly, a full screen was not carried out for CHEK2. Whilst 1100delC appears to be the major pathogenic allele in some European populations (for example, the UK), in others (for example, Poland) CHEK2 harbours additional pathogenic alleles with appreciable frequencies. We do not know where in this spectrum the population of the Netherlands falls because the number of Dutch subjects who have been completely mutation screened is quite small [8]. The proportion of carriers of deleterious mutations is, therefore, likely to be underestimated in this study. The impact of this is unclear; if these other mutations do not confer an increased risk of radiation-induced $\mathrm{BC}$, one could expect a reduction in the OR. If, on the other hand, the effect is greater than for those studied, the OR may be underestimated.

Of the four genes screened, the analysis of ATM was the most complete. Perhaps in order to make the ATM data more compatible with the limited sensitivity of the mutation screening for the other genes, the authors excluded from their risk calculations the ATM missense substitutions detected in this cohort. In a simultaneously published paper on the same study subjects, ATM missense substitution carriers appear to have a shorter latency of contralateral BC following radiation therapy than non-carriers [9], thus lending support to the hypothesis that rare missense sequence variants in ATM may also influence the risk of radiation-induced BC.

Another issue in the interpretation of these findings is the possibility that the choice of treatment protocols might be biased by clinico-pathological factors related to carrier status (even when it is unknown). For example, patients with estrogen receptor negative basal tumours may have received a more aggressive therapy because of their poorer prognosis, and it is known that BRCA1 carriers present with a disproportionate frequency of estrogen receptor negative basal tumours [10]. The authors report, however, that adjustment of the analyses for stage, size of tumour and lymph node involvement had little effect on the results (resulting ORs not shown).

It has been known for almost a decade that, after a first diagnosis of $\mathrm{BC}, B R C A 1$ and $B R C A 2$ mutation carriers have a very high risk of developing a second breast tumour [1113]. Because of the success rates of treatment, increasing numbers of women are surviving their first tumour. Five-year survival rates are about $75 \%$ in Europe [14]. The risk of developing a therapy-related tumour is, therefore, of increasing concern, both from the public health and patient management perspectives.

The GENE-RAD-RISK project, a large European study, is currently underway to evaluate whether carriers of pathogenic alleles in DNA repair and damage recognition genes may confer an increased risk of breast cancer following medical irradiation [15]. If, as suggested in this paper, the treatment is exacerbating the already disproportionate risk of second primary $\mathrm{BC}$ in mutation carriers, treatment protocols designed to minimize the risk of a second cancer need to be investigated in careful clinical studies.

\section{Conclusions}

While results of this and other recent studies still need to be confirmed, there is increasing evidence that carriers of pathogenic alleles in DNA repair and damage recognition genes may have an increased risk of BC following exposure to ionising radiation, even at low doses. This finding has important implications for the protection of patients and their close relatives.

If confirmed, mutation carriers may wish to consider alternatives to X-ray for diagnostic purposes, such as magnetic resonance imaging (MRI). The need for tailored cancer treatment strategies in carriers should also be evaluated carefully.

\section{Competing interests}

$\mathrm{EC}$ and $\mathrm{JH}$ declare that they have no competing interests. SVT is a previous employee of, and owns stock in, Myriad Genetics, Inc.

\section{References}

1. Ferlay J, Bray F, Pisani P, Parkin DM (eds): GLOBOCAN 2000: Cancer Incidence and Mortality Worldwide. Lyon: IARC Cancer Base No 5; 2001.

2. Ronckers CM, Erdmann CA, Land CE: Radiation and breast cancer: a review of current evidence. Breast Cancer Res 2005, 7:21-32.

3. UNSCEAR: Sources and Effects of lonizing Radiation. Volume 1: Sources. New York; UNSCEAR: 2000.

4. Walsh T, King MC: Ten genes for inherited breast cancer. Cancer Cell 2007, 11:103-105.

5. Andrieu N, Easton D, Chang-Claude J, Rookus MA, Brohet R, Cardis E, Antoniou AC, Peock S, EMBRACE, Noguès C, et al:: Low-dose ionizing radiation significantly increases the risk of breast cancer among BRCA1/2 mutation carriers in the IBCCS Study. J Clin Onco/ 2006, 24:3361-3366.

6. Bernstein JL, Teraoka SN, John EM, Andrulis IL, Knight JA, Lapinski R, Olson ER, Wolitzer AL, Seminara D, Whittemore AS, et al:: The CHEK2*1100delC allelic variant and risk of breast cancer: screening results from the Breast Cancer Family Registry. Cancer Epidemiol Biomarkers Prev 2006, 15:348-352.

7. Broeks A, Braaf LM, Huseinovic A, Nooijen A, Urbanus J, Hogervorst FB, Schmidt MK, Klijn JG, Russell NS, van Leeuwen FE, et al.: Identification of women with an increased risk of developing radiation-induced breast cancer: a case only study. Breast Cancer Res 2007, 9:R26.

8. Schutte M, Seal S, Barfoot R, Meijers-Heijboer H, Wasielewski M, Evans DG, Eccles D, Meijers C, Lohman F, Klijn J, et al:: Variants in CHEK2 other than 1100 delC do not make a major contribution to breast cancer susceptibility. Am J Hum Genet 2003, 72: 1023-1028.

9. Broeks A, Braaf LM, Huseinovic A, Schmidt MK, Russell NS, van Leeuwen FE, Hogervorst FB, 't Veer LJ: The spectrum of ATM missense variants and their contribution to contralateral breast cancer. Breast Cancer Res Treat 2007 Mar 28; [Epub ahead of print] doi: 10.1007/s10549-007-9543-6

10. Tischkowitz MD, Foulkes WD: The basal phenotype of BRCA1related breast cancer: past, present and future. Cell Cycle 2006, 5:963-967.

11. Frank TS, Manley SA, Olopade OI, Cummings S, Garber JE, Bernhardt B, Antman K, Russo D, Wood ME, Mullineau L, et al:: Sequence analysis of BRCA1 and BRCA2: correlation of mutations with family history and ovarian cancer risk. J Clin Oncol 
1998, 16:2417-2425.

12. Frank TS, Deffenbaugh AM, Reid JE, Hulick M, Ward BE, Lingenfelter B, Gumpper KL, Scholl T, Tavtigian SV, Pruss DR, et al:: Clinical characteristics of individuals with germline mutations in BRCA1 and BRCA2: analysis of 10,000 individuals. J Clin Oncol 2002, 20:1480-1490.

13. Haffty BG, Harrold E, Khan AJ, Pathare P, Smith TE, Turner BC, Glazer PM, Ward B, Carter D, Matloff E, et al.: Outcome of conservatively managed early-onset breast cancer by BRCA1/2 status. Lancet 2002, 359:1471-1477.

14. Breast Cancer in Europe [http://www.encr.com.fr/breast-factsheets.pdf]

15. The Gene-Rad-Risk Project [http://generadrisk.iarc.fr/index.php] 